\title{
The differential impact of observational learning and practice-based learning on the development of oral presentation skills in higher education
}

\begin{abstract}
The present study focuses on the design and evaluation of an innovative instructional approach to develop oral presentation skills. The intervention builds on the observational learning theoretical perspective. This perspective is contrasted to the traditional training and practice approach. Two experimental conditions - learners starting with observational learning versus learners starting with practice opportunities only- were compared in a crossover design. It was hypothesised that learners starting with observational learning would outperform learners in the practice only condition. The results suggest a significant differential impact on the development progress in oral presentation skills. This impact of the observational learning training approach is only found in a limited number of evaluation criteria. Results additionally suggest that students are highly motivated to learn this type of skills. Interaction effects between student characteristics and the instructional interventions were not significant.
\end{abstract}




\section{Introduction}

Oral presentation skills are considered key employability skills (Fallows \& Steven, 2000). As a result they are central in many higher education curricula and consequently the learning and instruction of oral presentation skills deserves investigation (e.g. Adams, 2004). According Taylor and Toews (1999), a focus on instruction introduces four key elements that define the learning environment: first learners need to know what to do, second they need to master the basic and conditional knowledge in view of concrete performance, third the beliefs of learners about their oral presentation skills should be considered, and fourth, learners should learn from their experience.

The first key element, discussed in many publications, is about defining what is important for presenters to know about good oral presentation skills. Some authors (Pittenger, Miller, \& Mott, 2004) use real-world standards, but many are based on common sense. Most publications emphasize the need to recognise performance aspects as well as content aspects (Fallows \& Steven, 2000) but Haber and Lingard (2001) stress the importance of context (purpose, audience and occasion) that determines content.

The second key element, - mastering the knowledge - is hardly treated in the literature, perhaps because this key element is not domain specific. Schraw (2006, p.256) describes the stages of skill acquisition with the knowledge acquisition stage where declarative knowledge is accumulated, and the knowledge construction stage where the knowledge is integrated into larger conceptual chunks.

The third key element, beliefs about oral presentation skills, can be interpreted as answering three questions by the presenters themselves (Miltiadou and Savenye, 2003). The first question 'Can I carry out this presentation task?' leads to the self-efficacy concept that is used in several studies about oral presentation skills (Adams, 2004). The second question 'Why am 
I doing this presentation task?' is connected with the goals set by the presenter. The last question 'how can I carry out this presentation task?' is related to the conceptions and knowledge learners have developed from the instruction phase.

The fourth and last key element, learning from experience, leads to the important concept of feedback, obtained through assessment from teachers, peers or through self-assessment. Many publications about learning oral presentation skills deal with feedback from these different sources (Langan et al., 2008). Peer assessment proves to be beneficial in learning oral presentation skills (Chen, 2010).

A comprehensive theoretical framework, comprising all the described instructional key elements is presented in section 2 .

\section{Theoretical framework}

The first key instructional element, stressed by Taylor and Toews (1999), about defining what is important to know about oral presentation skills, was approached on the base of a previously developed standardised multimedia instruction package and corresponding rubric. These are described in section 4. Research Design.

The remaining three key elements of the instructional environment (Taylor \& Toews, 1999), deal with how the oral presentation skills are learned and are combined in the following theoretical framework.

In the theoretical framework of the present study, teaching and learning oral presentation skills is approached from a social cognitive perspective on self-regulated learning (Zimmerman, 2000) and builds strongly on the social learning theory of Bandura (1986). This theoretical approach has commonly been adopted in competency training settings, such as behaviour modelling training and will guide the definition of our research questions in section 3. 
Bandura (2005) states that the learning process starts with social modelling experiences and develops via emulation to a self-controlled level (Zimmerman, 2000). This process implies that the first level is an observational level during which learners watch a model performing the skill to be acquired. When the learner tries -with assistance- to adopt the model behaviour, he moves to the emulation level. At the third level - the self-controlled level - the learner practices the behaviour independently of the model, but still in a structured setting. The selfregulated level is the fourth level where learners are able to adapt their performance to changing conditions.

Zimmerman (2000) exemplifies this learning process with a study about the acquisition of dart throwing skills. Learners in the modelling condition outperformed those that merely developed their skill on the base of extended practice.

Other studies come to comparable results, but in other knowledge domains: e.g., mathematics (Schunk \& Hanson, 1985), writing and reading (Couzijn, 1999) and in the domain of argumentative writing (Braaksma, Rijlaarsdam, \& Van den Bergh, 2002). No studies published until now, could be traced that build on experiments comparing modelling conditions with conditions based on extended practice in the domain of learning oral presentation skills.

In the cited studies, observational learners outperformed those that learned by mere practicing. This does not imply that participants from the latter group did not learn. Braaksma et al (2002) observed in this context the mediating impact of aptitude and prior knowledge. Medium level and good students -identified on the base of scores on two intelligence tests progressed in both conditions (observational learning versus learning by practicing) but weaker students profited more from observational learning (Braaksma et al., 2002). Students 
in the latter situation still needed to develop adequate initial cognitive representations. The modelling approach seems to be adequate in this context since it acts as a guide to perform complex behaviour (Bandura, 2005). The cognitive representation also serves as a standard for future corrective adjustments (Bandura, 2005) but this requires that learners can observe their own behaviour and interpret it correctly (Bandura, 1986). This introduces the three key sub-processes distinguished in self-regulated learning: self-observation, self-judgment and self-reaction (Schunk, 2001). Self-observation can be regarded as the first step in a learning process and has next to an informational, also a motivational function (Bandura, 1986). The information helps to set realistic performance standards and motivates learners to evolve depending on their outcome and efficacy expectations (Schunk, 2001). The basis for this change in behaviour (better performance) lies in the self-judgment process during which information gathered via self-observation is compared to the performance goal. If the learners attribute failure/success to an internal cause they can influence successfully, and it is worthwhile, then the learner will start a self-reaction process that brings the behaviour more in line with the performance standard. Motivation will depend on the anticipation of success or failure of the adapted behaviour (Schunk, 2001).

Personal characteristics, the third instructional key element of Taylor and Toews (1999) about the learners' beliefs, play an important role from the social learning perspective (Pintrich, 2003). The role of some personal characteristics is therefore briefly discussed. Students with a positive self-efficacy are more likely to work harder, are more persistent and attain higher achievement which generally raises self-efficacy (Bandura, 1997). Goal constructs have been researched from two different perspectives: goal content and goal orientations (Pintrich,2003). Social cognitivists showed that proximal, specific, moderately difficult and self-set goals have the strongest impact on motivation (Schunk, Pintrich, \& Meece, 2007). Goal orientations embrace mastery goal orientations (focus on learning) and performance goal orientations 
(focus on demonstrating competence or ability). An important distinction is made between approach performance goals and avoidance performance goals. Avoidance performance goals often lead to lower levels of performance (Schunk et al., 2007).

Students perceptions of the learning environment are also important, because students react to transformed and interpreted stimuli (Lowyck, Elen, \& Lehtinen, 2004).

The former set of theoretical assumptions help to position the results found in earlier studies. Results from ... (name deleted for review) (2009b) pointed at the critical position of motivational constructs, such as self-efficacy, attribution and goal orientation in developing oral presentation skills. The study especially focussed on the significant positive impact of self-generated focused learning goals as compared to general learner goals. These findings influenced the design and development of a goal-directed standardised multimedia instruction approach resulting in significant learning gains (name deleted for review, 2009a). However, questions were raised as to the potential of simply giving opportunities to practice presentation skills.

Bandura (1986) makes a clear distinction between acquisition and performance because learners do not always demonstrate what they learned. This is especially the case when what is learned has little functional value, and when weak performance will result in negative reinforcement (Schunk, 2001). Modelling is again helpful in this context, since observing a model performing the expected behaviour without observing negative consequences will influence the probability that this behaviour will be executed. 
When turning to the context of higher education curricula, the question can be raised whether the theoretical framework described above holds when applied to the learning of oral presentation skills. If the latter is the case, the assumption can be made that students have already observed many oral presentations, and it could be expected that they function at the third or fourth level in their development of oral presentation competences. On the base of what they observe and personally deliver, it can be hypothesized that they can mobilise sufficient basic cognitive representations guiding their attempts to give a presentation without help from faculty. If the latter hypothesis is confirmed, this implies that learners have experienced a sufficient level of observational learning and that they only need additional opportunities for practice. The assumptions about the self-monitoring capacities of these students elicit some questions. For example, is it possible to be so confident about the nature and quality of available cognitive representation about good or effective oral presentations? Did learners receive adequate corrective feedback in view of adjustment of their strategies? Are they sufficiently aware of the standards and the expected performance level? If the last question is answered in a negative way, this introduces the need for additional observational learning focusing on the acquisition of the standards before turning to practice. An additional question looks at student characteristics that mediate the instructional impact. Are the students e.g., sufficiently motivated to bridge the gap between the standards and their personal performance level? How is their self-efficacy as to giving oral presentations? Do they attach a high value to this task? Are students still inhibited to give oral presentations? This long list of questions is especially valid when students haven't been involved in a systematic and performance oriented learning process that reflects the sub-processes normally resulting in self-regulated learning (Schunk, 2001): self-observation, self-judgment, and self-reaction.

\section{Research questions}


On the base of the theoretical framework and the results of earlier studies, the following research questions were raised:

- Will oral presentation skill performance improve due to a combination of observational learning and individual practice?

- Will participation in the observational learning condition result in higher oral presentation skills compared to participation in the practice condition only?

- What are the interaction effects of student characteristics (goal orientation, personal performance estimation, perception of instruction and learning) on the impact of the instructional interventions? What is the interaction effect of student characteristics (goal orientation, personal performance estimation, perception of instruction and learning) on the relationship between the instructional interventions and the dependent variables?

\section{Research Design}

In view of testing the research questions, a pretest-posttest cross-over design was set up. Instead of defining a straightforward traditional experimental-control design, a cross-over design was adopted in view of ethical considerations related to giving all students equal instructional opportunities.

\section{Participants}

The 38 participants (32 female and 6 male) were students from a (Dutch speaking) Belgian university college enrolled in two different programs: 
- 15 participants (11 female) were university freshman enrolled for a Business Administration introductory course about psychology, including a section about communication and presentation skills

- 23 participants (21 female) were second year students from the linguistics and literature department enrolled for a course about communication and presentation skills.

It was assumed that students from both groups had the same level of proficiency in terms of oral presentation skills, because they did not differ in terms of initial training about presentation skills. Prior to this study, participants from both groups had never been enrolled in a course focusing on the training and development of oral presentation skills. Nevertheless, in other courses, some of them had been invited to deliver short oral presentations/communications; e.g., in the context of their foreign language courses. But this was not based on a systematic instructional intervention, neither were the presentation goals geared towards assessment of their presentation skills.

The sample was selected randomly from a total of 51 Business Administration Students and 63 Linguistics students. However some students did not deliver three presentations or failed to fill out a questionnaire. A critical hurdle was caused by the amount of time peers could spend assessing the oral presentations.

\section{Research instruments}

Participants were invited to fill out a set of research instruments at the start (questionnaire 1) and at the end (questionnaire 2) of the research procedure. These instruments focused on the participants' goal orientations, personal performance estimation, perception of peer assessment and reflections on the learning process.

\section{Questionnaire 1: Personal characteristics}


Goal orientation measure: PALS. The most recent version of the Patterns of Adaptive Learning Survey (Midgley et al., 2000) consists of three 5 or 4 item subscales that represent three goal orientations (task goal, performance approach, and performance avoidance). The revised version of the PALS was translated into Dutch following the 'parallel blind technique' (Behling \& Law, 2000).

Personal performance estimation. The participants were asked to evaluate and score their personal oral presentation on the base of a rubric developed during a pilot study. In this pilot study four experts used six available scales to assess videotaped student performances. In addition, a semi-structured interview was organized with each expert. These interviews were analyzed in order to develop a rubric that builds on nine criteria: three content-related criteria (introduction, structure, and conclusion), five focusing on presentation performance or delivery (eye-contact, vocal delivery, enthusiasm, interaction with the audience and bodylanguage), and one overall assessment item (professionalism).

The item "professionalism" invites students to measure in a general way the quality level of their oral presentation on a 5 point Likert scale. Concrete indicators were made available to support the scoring along the five performance levels. The use of such a general assessment item, is supported by the literature (Thomson \& Rucker, 2002, p.23).

Perception of 'peer assessment'. In the former study (name deleted for review, 2009a), some students expressed concerns about the fact that their oral presentations were also assessed and scored by peers, To measure student perceptions about peer assessment, an instrument constructed and validated by Sluijsmans (2002) was adopted. The original subscale consisted of 7 items, with an alpha reliability coefficient of .74. One item was omitted and a few words were changed to adapt the subscale to the specific oral presentation situation. The reliability 
of the adapted subscale was comparable to alpha-values of the original subscale, .78 (first questionnaire) and .74 (second questionnaire). More information is provided in table 1.

\section{Questionnaire 2: Reflections on the learning process}

Items were rated on a five-point Likert scale. Items dealt with:

(1Characteristics of the learning process: How much time did you spend preparing the presentation? How much did you like/learn from the following (seven) instructional elements (ten-point Likert scale)? Did you consult others during the preparation of your presentation?

(2) Perceptions of peer assessment subscale from the first questionnaire.

(3) Perceptions regarding their learning progress:. Did the instruction result in the acquisition of knowledge, skills, self-confidence (seven-point Likert scale)? Two internal and three external attributions (seven-point Likert scale).

\section{Research procedure}

Figure 1 gives a flowchart of the research procedure. Participants were assigned randomly to one of the two research condition. These conditions differ in the adoption of a standardised multimedia instruction. In the first condition, the instruction is given after the first oral presentation. In the second condition the instruction is given after the second oral presentation. All oral presentations were videotaped. 
Figure I. Overview of the research procedure

Condition 1: Observational learning first $(n=21)$

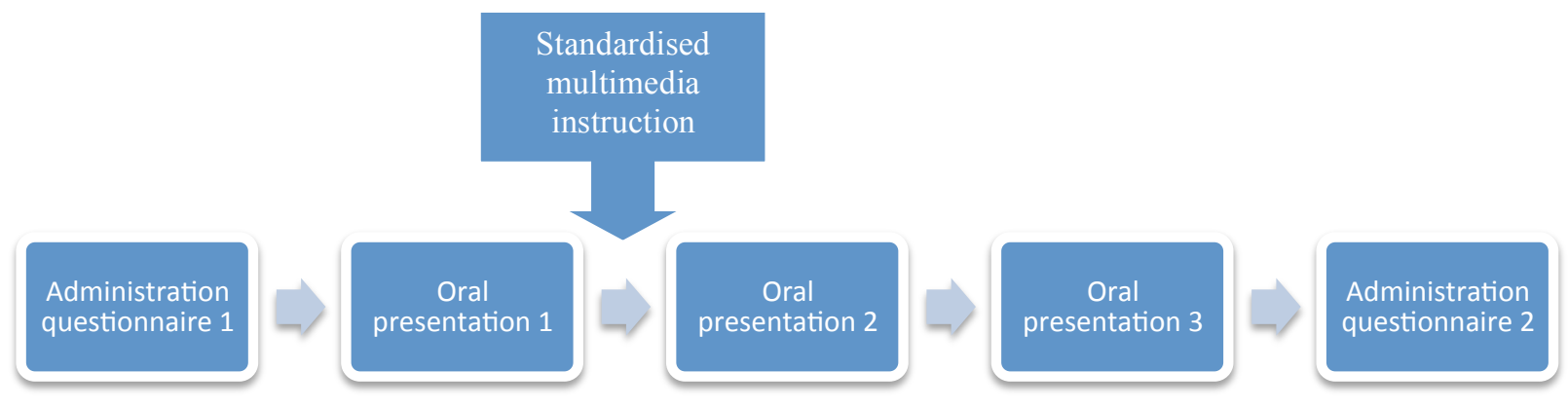

Condition 2: Learning from practice first $(n=17)$

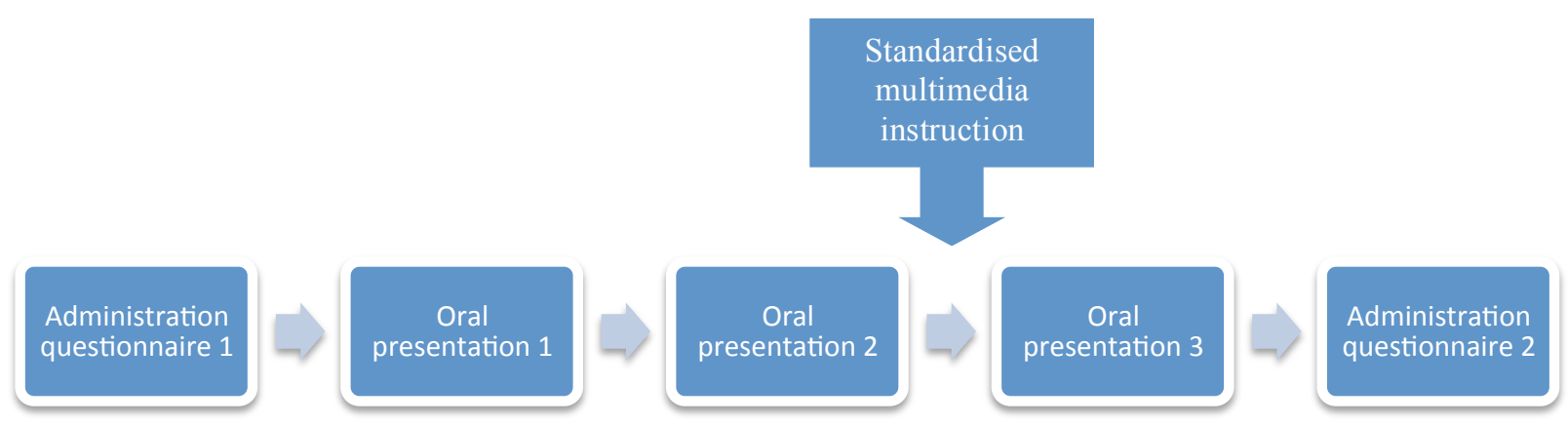

The three oral presentations were evaluated and scored by peers. Only the data from participants from whom three presentations were assessed by a minimum of four peers, are included in this study. The latter decision is based on the results of ...(name deleted for review) (2009a) in which was found that four peer judgments result in sufficiently reliable scores. Peers only assessed oral presentations from students they were not acquainted with (. In addition, peers did never assess more than one presentation of one and the same student.

\section{Observational learning through the standardised multimedia instruction}


In order to support observational learning, short video clips were presented illustrating behaviour in relation to the nine rubric criteria discussed above. The collection of video clips was incorporated into a computer-based multimedia instructional package about the do's and don'ts of an oral presentation. Figure 2 presents some screenshots from the multimedia package.

Figure 2: Two screen-dumps of the multimedia instructional package.

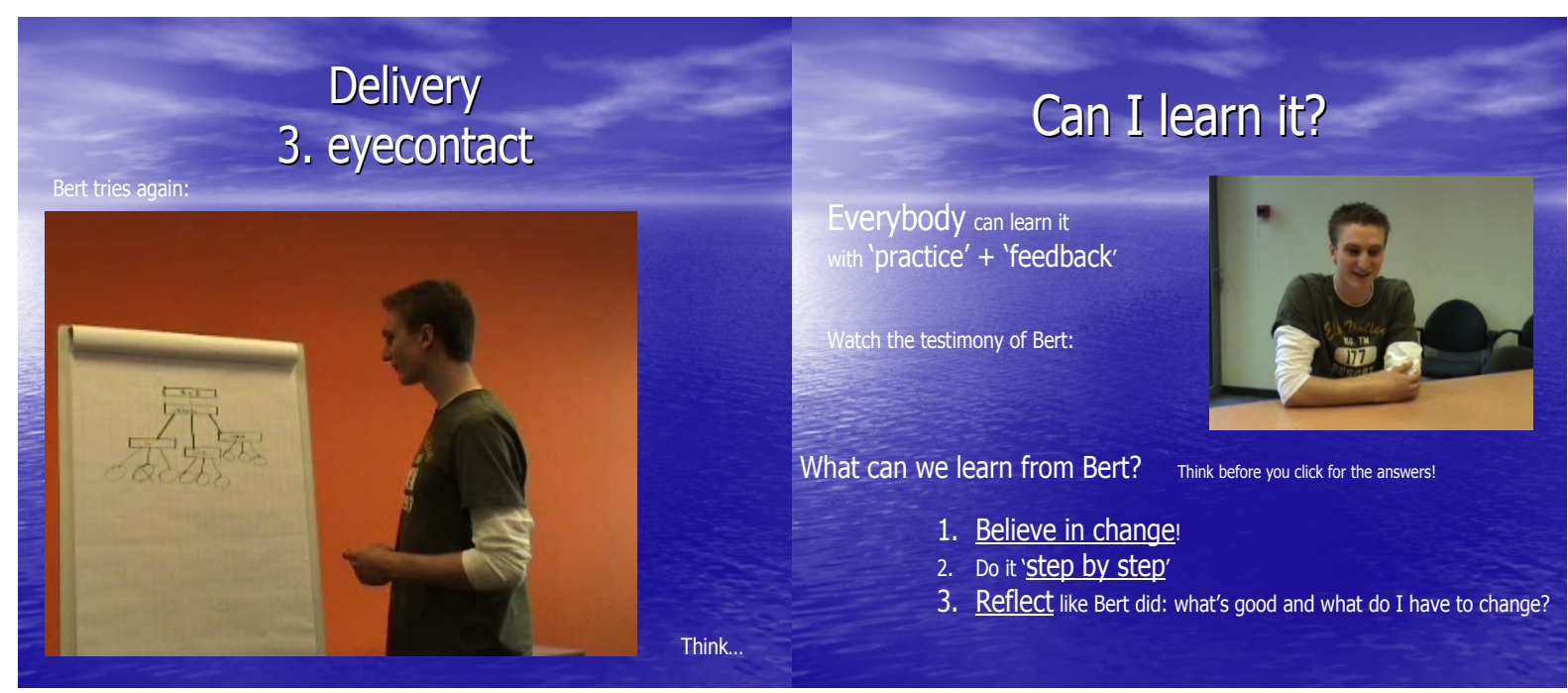

The total package consisted of four parts.

In the first part, an answer is given to the question "why should I learn how to present?" The content reflects a mastery goal orientation and a performance approach goal orientation and builds on the testimonial of a female manager demonstrating that oral presentation skills are highly valued in professional life.

The second part builds on the testimonial of a male student and focuses on learning strategies. In line with the theoretical framework (Bandura, 1997), the social model tells about the difficulties he had in dealing with the presentation assignment and how he reflected on his learning strategy, changed it, and was successful in the end (applause from audience and complimented by the teacher). Tucker and McCarthy (2001) report that such a testimony can enhance self-efficacy, and this can be a motivational construct predicting presentation 
performance (name deleted for review, 2009b). The model also stressed the importance of self-chosen, proximal, and attainable goals (Schunk, 2001). He also attributed success to practicing. Such internal attributions have a positive impact on motivation and performance (Eccles \& Wigfield, 2002).

In the third and main part of the instruction, the nine criteria of the assessment instrument (cfr. supra) are illustrated with 14 subsequent, but related video clips. Based on comparable studies (Baldwin, 1992), a mixture of social models (gender and age groups) was involved to perform the desirable behaviour ( 9 video clips) and undesirable behaviour ( 5 video clips). In order to stimulate reflection, participants are asked after each video clip to think about what they observed and then to click for additional information.

In the fourth and last part of the instruction, students got the opportunity to practice the application of the assessment criteria. This part reflects the third set of processes in observational learning (Bandura, 1997). Participants are invited to assess a recorded presentation, on the base of the nine criteria presented earlier.

In Figure 3 a short overview of the different sections in the instructional package is presented. 
Figure 3. Overview of the multimedia package

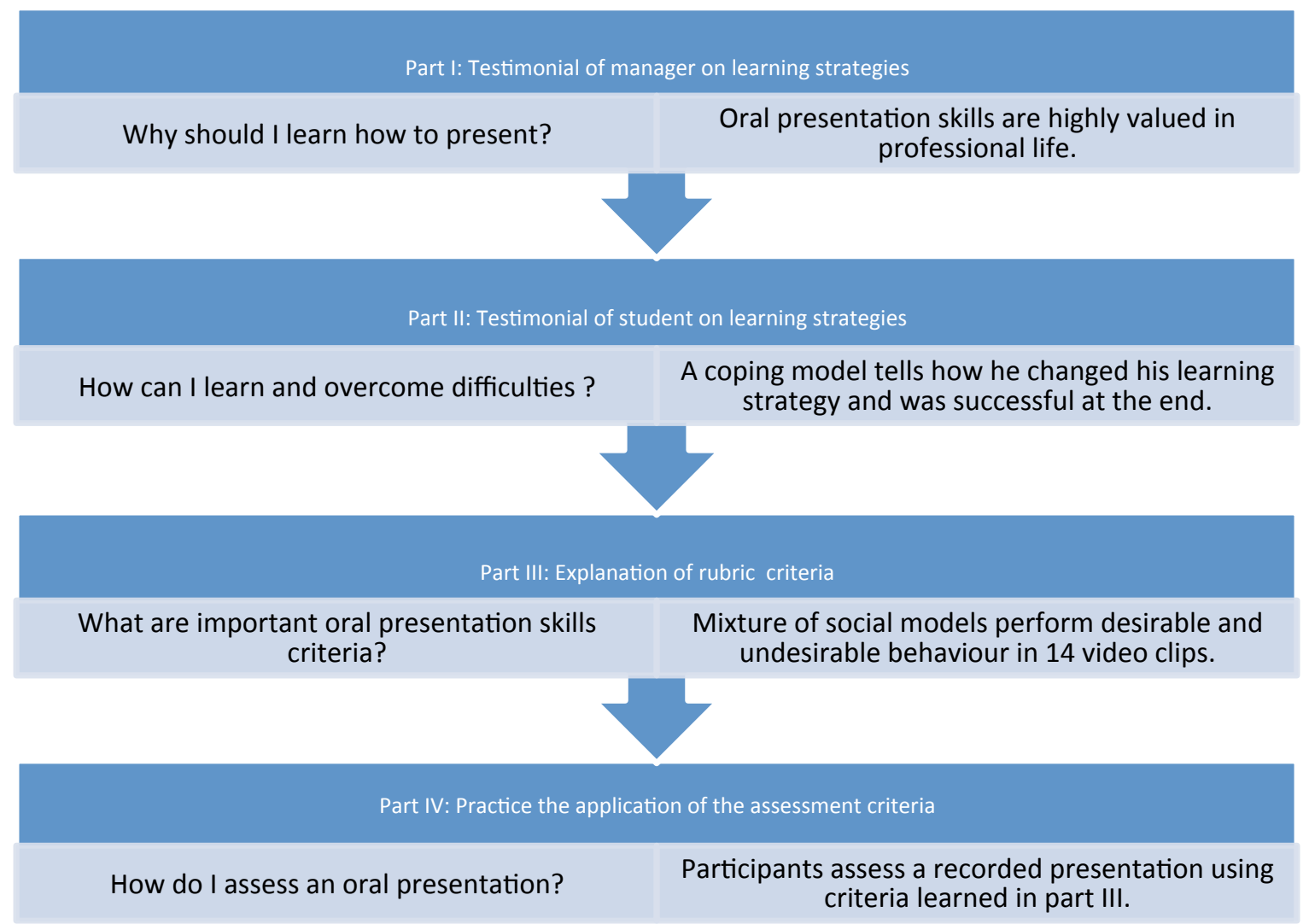

\section{Research Results}

\section{Quality screening of the research instruments}

Kolmogorov-Smirnov tests were conducted to analyse whether score distributions were normally distributed. When score distributions were not normal the nonparametric equivalents of $t$-test and correlations were used for these subscales. In addition reliability indices were calculated. Table 1 summarizes the analysis results. These reflect acceptable to good reliability indices. 
Table 1. Psychometric quality of scales and subscales

\begin{tabular}{|c|c|c|c|}
\hline Subscales & $\alpha$ & $M$ & $S D$ \\
\hline 1 PALS task goal ${ }^{\mathrm{a}}$ & .66 & 4.60 & 0.42 \\
\hline 2. PALS performance approach & .72 & 2.34 & 0.58 \\
\hline 3. PALS performance avoid & .70 & 3.22 & 0.81 \\
\hline 4.Perception of peer assessment (first questionnaire) & .78 & 4.14 & 0.62 \\
\hline 5. Perception of peer assessment (second questionnaire) & .74 & 4.22 & 0.50 \\
\hline 6. Personal performance estimation & .84 & 2.81 & 0.52 \\
\hline 7. Qualitative preparation & .70 & 2.67 & 0.77 \\
\hline 8. Quantitative preparation & .89 & 2.27 & 0.73 \\
\hline 9. Appreciation of the instructional intervention & .83 & 6.26 & 1.27 \\
\hline 10. Learning from the instructional intervention & .83 & 6.60 & 1.26 \\
\hline
\end{tabular}

The key dependent variable in this study is the quality of the oral presentations. The 114 oral presentations (three for each participant) were, as described earlier, assessed by 4 peers. The mean of the peer assessment scores was calculated. A two-facet generalizability study, based on the analysis procedure of Mushquash and O'Connor (2006), was conducted to estimate the inter-peer agreement The generalizability study, produced a generalizability coefficient of .89 when building the reliability index on four peers and nine assessment criteria. This is above the threshold of $G>.80$ criterion (Mushquash \& O'Connor, 2006). This implies that on the base of the mean score, calculated from the four peer assessment scores, we obtain a reliable measure of oral presentation skills. 
Because most assessment instruments discern two subscales -content and performance (or delivery)- three different sum scores were developed: a total sum based on the nine rubric criteria $(\alpha=.83)$, a sum score based on the three content-related criteria $(\alpha=.62)$ and a sum score based on the five delivery-related criteria $(\alpha=.77)$.

\section{The impact of observational learning and individual practice on oral presentation}

\section{performance}

A repeated-measures analysis of variance with Greenhouse-Geiser correction was carried out to assess the within-subjects main effect of observational learning and practice on the quality of the three successive oral presentations. Results point at a significant increase in overall (sum of the nine criteria) performance, $F(1.88,67.85)=36.09, p<.001$, partial eta $^{2}=.50$, in relation to the presentation content quality, $F(1.91,68.70)=25.62, p<.001$, partial eta ${ }^{2}=.42$, and in relation to the presentation delivery quality, $F(1.82,65.56)=16.23, p<.001$, partial $e t a^{2}=.31$

Table 2 summarizes the results of t-tests and Wilcoxon signed ranks tests that clarify the progress between the three oral presentations. Results reveal that performance increased significantly for seven out of nine oral-performance criteria between the first and third oral presentation. In terms of effect size, the growth can be considered to be very large for the subscale conclusion $(t=5.64, p<.001, d=1.22)$ and interaction with audience $(t=6.99, p<$ $.001, d=0.92)$. The growth is rather small for eye contact $(t=.45 p=.66, d=0.07)$ and vocal delivery $(t=1.88, p=.07, d=0.34)$. The overall picture of progress made between presentation one and two is very similar to that of the progress made between presentation one and three, but the effect sizes are smaller for most of the criteria. The progress between 
presentation two and three is rather restricted, except for the subscale conclusion $(t=3.19, p<$ $.001, d=0.60)$.

Table 2. Scores $(\mathrm{N}=38)$ on the three oral presentations (=pres)

Mean, t-tests / Wilcoxon signed ranks tests, effect size

\begin{tabular}{|c|c|c|c|c|c|c|c|c|c|}
\hline assessment & & & & $t / Z$ & & $t / Z$ & & $t / Z$ & \\
\hline criteria & & pres. 2 & pres. 3 & pres. 1 - 3 & $d$ & pres. 1 - 2 & $d$ & pres. 2- 3 & $d$ \\
\hline Introduction & $2.72(.51)$ & $3.02(.50)$ & $3.13(.58)$ & $4.77^{\star \star}$ & 0.75 & $3.18 * *$ & & $\underline{1.01}$ & \\
\hline Structure & $2.92(.56)$ & $3.10(.46)$ & $3.32(.56)$ & $3.88^{* *}$ & & $2.14^{*}$ & 0.37 & $2.16^{*}$ & \\
\hline Conclusion & $2.26(.53)$ & $2.58(.59)$ & $2.93(.58)$ & $5.64^{* *}$ & 1.22 & $3.22 * *$ & 0.57 & $3.19 * *$ & 0.60 \\
\hline Interaction audience & $2.74(.48)$ & $3.17(.48)$ & $3.22(.56)$ & $6.99^{* *}$ & 0.92 & $7.36^{* *}$ & 0.90 & 0.63 & 0.10 \\
\hline Enthusiasm & $2.72(.62)$ & $3.05(.61)$ & $3.11(.68)$ & $4.52^{* *}$ & 0.58 & $4.41 * *$ & 0.52 & 0.83 & 0.09 \\
\hline Eye-contact & $3.36(.81)$ & $3.51(.66)$ & $3.41(.61)$ & 0.45 & 0.07 & 1.48 & 0.20 & 1.06 & -0.16 \\
\hline Vocal delivery & $3.20(.51)$ & $3.30(.56)$ & $3.37(.49)$ & $2.14^{*}$ & & 1.57 & 0.19 & $\underline{1.05}$ & \\
\hline Body language & $2.91(.51)$ & $3.25(.58)$ & $3.24(.67)$ & $3.04^{*}$ & 0.55 & $3.94 * *$ & 0.62 & 0.09 & -0.02 \\
\hline Professionalism & $2.85(.53)$ & $3.07(.44)$ & $3.28(.45)$ & $\underline{4.59 * *}$ & & $3.27 * *$ & 0.45 & $\underline{3.38 * *}$ & \\
\hline Sum score content & $2.63(.41)$ & $2.91(.41)$ & $3.13(.48)$ & $7.23^{* *}$ & 1.12 & $4.30 * *$ & 0.68 & $2.95 * *$ & 0.49 \\
\hline Sum score delivery & $2.99(.49)$ & $3.25(.47)$ & $3.27(.50)$ & $4.57^{* *}$ & 0.57 & $5.60 * *$ & 0.54 & 0.34 & 0.04 \\
\hline Sum score of 9 criteria & $2.85(.44)$ & $3.12(.40)$ & $3.23(.44)$ & $7.57^{* *}$ & 0.87 & $6.22 * *$ & 0.64 & $2.69 *$ & 0.26 \\
\hline
\end{tabular}

Note: underlined results apply to Wilcoxon signed ranks tests

$* \mathrm{p}<.05, * * \mathrm{p}<.01$ 
Will participation in the observational learning condition result in higher oral presentation skills compared to participation in the only getting practice condition?

Results of the repeated-measures analysis of variance (Greenhouse-Geiser correction) with the two research conditions as the between subject factor, indicate that there is no overall significant differential effect, $F(1.88,67.85)=0.41, p=.65$. The progress made between presentation one and three is about $13 \%$ for participants in both conditions. This implies that the overall progress achieved by participants that start with observational learning before getting opportunities to practice, is not significantly different from the progress made by participants that first started practicing before observational learning.

A significant difference was found in relation to content criteria. Participants starting with observational learning progress to a larger extent in content related criteria between presentation one and two (13.79\%) but made only a small progress between presentation two and three (4.27\%). Participants starting with practicing made only a small progress between presentation one and two $(5.87 \%)$ but progressed strongly between presentation two and three after observational learning (12.37\%).

Further analysis of the impact on the three specific content related criteria reveals a significant interaction effect on the quality of the conclusion in both experimental conditions, $F(1.81$, $64.99)=3.87, p=.03$, partial $e^{2} a^{2}=.10$. The results of a split file analysis based on the two experimental conditions show that the group receiving observational learning first, progressed significantly larger between presentation one and two $F(1,20)=21.05, p<.001$, partial $e t a^{2}=.51$ and in a non-significant way between presentation two and three $F(1,20)=1.35, p$ $=.26$, partial eta ${ }^{2}=.06$. In contrast, participants in the "practice first" condition mirror an 
insignificant progress between presentation one and two $F(1,16)=.001, p=.98$, partial $e t a^{2}=.00$, but a significant progress between presentation two and three $F(1,16)=14.00, p$ $=.002$, partial eta $^{2}=.47$.

\section{Student characteristics}

Participants report a strong task goal orientation $(M=4.60)$ and are moderately motivated to learn oral presentation skills $(M=3.56)$. When asked what instructional elements influenced their oral presentation performance, they put preparation first $(M=6.47)$, nature of the topic second $(M=5.34)$ and their ability third $(M=4.89)$. Although "preparation" is rated first, there's no significant correlation between perceived increase in oral presentation skills and time spend on preparation of the presentation (Spearman $r=-.32, p=.08$ ). Very few participants (only 12\%) asked others for help preparing their presentation.

They also hold a very positive view about peer assessment $(M=4.22)$.

Results show a clear gain in knowledge acquisition $(M=5.54)$, progress in oral presentation skills $(M=5.44)$ and an increase in self-confidence $(M=5.18)$. There is a significant correlation between observed progress in oral presentation skills and increase in self-confidence (Spearman $r=.41, p=.01$ ) but no significant correlation between gain in knowledge acquisition and increase in self-confidence (Spearman $r=.09, p=.62$ ). There's also no significant correlation between gain in knowledge and increase in oral presentation skills (Spearman $r=.16, p=.36$ ). The correlation between perceived progress in presentation skills and actual progress (assessed by peers) between presentation one and three is not significant (Spearman $r=.07, p=.67$ ).

Interaction effects of student characteristics 
Linked to the analysis results in relation to the second research question, no significant interaction effects are observed between learner characteristics and instructional interventions on oral presentation performance. The $A N C O V A$ results show for the personal performance estimation $F(2,20)=, 79, p=, 47)$; for task goal $F(2,20)=2,4, p=, 12)$; for performance avoidance $F(2,20)=1,11 p=, 35)$; for performance approach $F(2,20)=, 46, p=, 64)$; for perception of peer assessment $F(2,20)=, 44, p=, 65)$.

\section{Discussion and conclusions}

With regard to the first research question about the overall impact of observational learning and practice on the acquisition and development of oral presentation skills, it is clear that the quality of the third oral presentation was higher. Consequently the application of the theoretical framework, described in section 2. (Theoretical framework), to the domain of the learning of oral presentation skills proved successful. The improvement was apparent in relation to all criteria, but progress was larger at content level as compared to the delivery level. It seems e.g., more difficult to influence eye contact with the audience ( $M=3.36$ in the first and $M=3.41$ in the third presentation) as compared to influencing the quality of the conclusion ( $M=2.26$ in the first and $M=2.93$ in the third presentation). This is in line with previous research results (name deleted for review, 2009a). We have to bear in mind that the mean scores for eye contact and vocal delivery can hide individual differences due to the position of the assessor in the lecture theatre. A voice can be easily heard at the front, but can be inaudible at the rear (Hughes \& Large, 1993), and a presenter can make eye contact with the left side of the audience, but not with students at the right side.In order to study the differential impact of observational learning versus practice-based learning, two experimental conditions were compared in a cross-over design. It was hypothesised that, like in several 
other studies in domains - such as. writing (Braaksma et al, 2002) - learners starting with observational learning would outperform learners starting with practice opportunities only. This hypothesis was only partly confirmed, since no overall significant impact could be observed (see 6. Research Results). But, participants starting with the observational learning strategy attained a higher level in relation to the oral presentation content criteria; such as quality of the conclusion. The cognitive perspective about self-regulated learning (Zimmerman, 2000) offers some possible explanations for these results. These explanations have to be considered as assumptions that need further investigation. One possibility is that in general - knowledge about the quality of a conclusion was new for all participants. This implies that - despite earlier practice with oral presentations - no cognitive representations were readily available to build upon. Learners in the observational learning condition could therefore profit in an immediate way from the modelling in the standardised multimedia instruction. This facilitated learning at the observational level. The latter was not the case with learners in the practice condition. The lower impact of the multimedia instruction can also be explained in a second way. Participants did learn new aspects of good oral presentations, but had difficulties with "making the unobservable observable" (Bandura, 1986, p.66). While preparing and delivering oral presentations students have to observe themselves before making a judgment about their performance in view of making adjustments. This cyclical process might be easier in relation to the criterion quality of the conclusion as compared to e.g., use of body language. The quality of a conclusion can be analysed, compared with standards and adjusted during a preparation phase, but this is much more complicated for the quality of body language. Most students do not prepare in front of an audience (only $12 \%$ admitted consulting others), and do not tape their presentation during rehearsal. This limits their possibilities for self-observation and consequently implies that there is a rather weak meta-cognitive monitoring of the quality of the level of eye contact. Students are not 
stimulated to consider requirements for a good level of eye contact and do not develop a specific goal targeting this element of oral presentation performance. They consequently also do not develop a strategy to ameliorate their eye contact. It is even possible that learners adopt incorrect behaviour but assume that it is consistent with the standards and find this incorrect behaviour rewarding. Even if learners know the standards and can accurately judge their presentation performance, they will not automatically pursue these standards. They have to be convinced that they can learn the new behaviour and need a sufficient level of selfefficacy, and attribute progress to internal and changeable causes.

Thirdly, inhibition can have played a role. Participants can be inhibited to behave in line with criteria because of fear for the reactions of the audience. Changing the way to keep eye contact with the audience can be more threatening than changing the conclusion in an oral presentation. It can be concluded that delivering a good oral presentation depends on many sub skills and that it is likely that learners have attained a different level in relation to specific sub skills. Since it is necessary to adapt the instruction to the level of the learner in an observational learning process, the standardized multimedia package might have been less effective in view of influencing specific oral presentation criteria. Learners need a coping model at observational level, but a mastery model at emulation level, process goals to attain the self-control level and outcome goals in view of attaining the self-regulation level (Zimmerman \& Kitsantas, 2002).

In relation to the third research question about student characteristics, there is no evidence of interaction effects. It can however be concluded that learners are convinced that learning oral presentation skills is important and that they can learn it. This reflects promising motivation levels (Bandura, 1986). Participants are also very positive about learning effects of peer assessments. 
Participants report a perceived increase in knowledge about oral presentations, and in oral presentation skills. However no correlation was found between these perceptions, which can be due to the small number of participants involved in the study. We hypothesize that participants make a distinction - already suggested by Bandura (1986) - between knowing and performing. As indicated in the theoretical framework, Bandura states that learners do not always demonstrate what they learned. This suggests that our participants feel self-confident it they demonstrate what they "know" about good oral presentations. This explains why we observe no correlation between perceived gain in knowledge acquisition and perceived increase in skills and why we observe no significant correlation between perceived knowledge gain and self-confidence. Participants only express confidence when they perceive higher performance. This fits the findings of Bandura (1997) that successful performance - in general - raises self-efficacy. The fact that participants feel they learned new skills, and additionally attained a higher self-confidence level, is an important element in the motivation cycle to attain self-reaction (Schunk, 2001).

The negative - but non-significant - correlation between reported preparation time and actual progress made in oral presentation is at first sight remarkable but Gibbs and Simpson (2004) warn that perception of effort depends more on student motivation than on actual number of hours spend during preparation. Gibbs and Simpson also warns that learners might use their time unproductively.

The discrepancy between observed and actual progress demonstrates that it is important to take into account the perception of learners. This discrepancy can also be viewed from a goal orientation perspective. Results show that participants have a strong task goal (or mastery) orientation and by pursuing these goals they try to develop their ability and define success with self-referential standards ( Senko, Durik, \& Harackiewicz, 2008, p.100). These standards can differ from the standards of the rubric used by peers to assess oral presentations. This 
could partially explain the difference between perceived and actual progress in oral presentation skills.

It is clear that developing oral presentation skills requires a complex interplay of cognitive and motivational processes. This complex reality exceeds the design of this study that involved a limited number of participants during a limited period of time. Nevertheless some interesting results emerged that are helpful to direct future research. These studies will require the involvement of larger groups, during a longer research intervention, and with a focus on middle term and long term effects. Further research could also take into account other factors, such as individual differences that impact oral presentation skills. Additionally, also the modelling approach can be refined by introducing for example corrective modelling after giving personal feedback (Bandura, 1986).

\section{References}

Adams, K. (2004). Modelling success: enhancing international postgraduate research students' self-efficacy for research seminar presentations. Higher Education Research and Development, 23(2), 115-130.

Baldwin, T. (1992). Effects of alternative modelling strategies on outcomes of interpersonalskills training. Journal of Applied Psychology, 2, 147-154.

Bandura, A (1986). Social foundations of thought and action. A social cognitive theory. Englewood Cliffs, NJ: Prentice-Hall.

Bandura, A. (1997). Self-efficacy: the exercise of control. New York: Freeman.

Bandura, A. (2005). The evolution of social cognitive theory. In K. Smith \& M. Hitt (Eds.). Great minds in management (pp.9-35). Oxford: Oxford University Press. 
Behling, O., \& Law, K. (2000). Translating questionnaires and other research instruments: problems and solutions. Thousand Oaks: Sage.

Braaksma, M., Rijlaarsdam,G., \& Van den Bergh, H. (2002). Observational learning and the effects of model observer similarity. Journal of educational psychology 94 (2), 405-415.

Chen, C. (2010). The implementation and evaluation of a mobile self- and peer-assessment system. Computers \& Education, 55, 229-236.

Couzijn, M. (1999). Learning to write by observation of writing and reading processes: effects on learning and transfer. Learning and Instruction, 9, 109-142.

Eccles, J., \& Wigfield, A. (2002). Motivational beliefs, values, and goals. Annual Review of Psychology,. 53, 109-132.

Fallows S., \& Steven, C. (2000) Building employability skills into the higher education curriculum: a university-wide initiative. Education + training; 42 (2), 75-82.

Gibbs, G., \& Simpson, C. (2004). Conditions under which assessment supports students' learning. Learning and Teaching in Higher Education, 1, 3-31.

Haber R., \& Lingard, L. (2001). Learning oral presentation skills. A rhetorical analysis with pedagogical and professional implications. J. Gen. Intern.Med., 16, 308-314.

Hughes,I., \& Large,B. (1993). Staff and peer-group assessment of oral communication skills. Studies in Higher Education, 18(3), 379-385.

Langan, M., Shuker, D., Cullen, R., Penney, D., Preziosi, R., \& Wheater, P. (2008). Relationships between student characteristics and self-, peer and tutor evaluations of oral presentations. Assessment \& Evaluation in Higher Education, 33(2), 179-190.

Lowyck, J., Elen, J., \& Lehtinen, E. (2004). Students' perspectives on learning environments. Guest editorial. International Journal of Educational Research, 41, 401-406.

Midgley et al. (2000). Manual for the Patterns of Adaptive Learning Scales (PALS). Available online at: http://www.umich.edu/ p pals/ (accessed 17 May 2006). 
Miltiadou, M., \& Savenye, W. (2003). Applying social cognitive constructs of motivation to enhance student success in online distance education. Educational Technology Review, 11(1).

Mushquash, C, \& O’Connor, B. (2006). SPSS and SAS programs for generalizability theory analyses. Behavior Research Methods, 38(3), 542-547.

Pintrich, P.(2003). A motivational science perspective on the role of student motivation in learning and teaching contexts. Journal of Educational Psychology, 95 (4), 667-686.

Pittenger. K., Miller, M., \& Mott, J. (2004). Using real-world standards to enhance students' presentation skills. Business Communication Quarterly, 67(3), 327-336.

Schraw, G. (2006). Knowledge: structures and processes. In P. Alexander, \& P. Winne (Eds.), Handbook of educational psychology. Second edition (pp.245-263). Lawrence Erlbaum, Mahwah, New Jersey.

Schunk, D. (2001). Social cognitive theory and self-regulated learning. In B. Zimmerman \& D. Schunk (Eds.). Self-regulated learning and academic achievement. Theoretical perspectives (pp.125-151). Mahwah, NJ: Lawrence Erlbaum.

Schunk, D., \& Hanson, A. (1985). Peer models: influence on children's self-efficacy and achievement. Journal of Educational Psychology, 77(3), 313-322.

Schunk, D. , Pintrich, P. , \& Meece, J. (2007). Motivation in education. Theory, research and applications. $3^{\text {rd }}$ edition. Pearson education.

Senko, C., Durik, A., \& Harackiewicz, J. (2008). Historical perspectives and new directions in achievement goal theory. Understanding the effects of mastery and performance-approach goals. In J. Shah, \& W. Gardner (Eds.), Handbook of motivation science (pp. 100-113). New York: The Guilford Press.

Sluijsmans, D. (2002). Student involvement in assessment. The training of peer assessment skills. Unpublished doctoral dissertation, Open University of the Netherlands, Heerlen. 
Taylor, K., \& Toews, S. (1999). Effective presentations: how can we learn from the experts? Medical Teacher, 21(4), 409-414.

Thomson, S., \& Rucker, M. (2002). The development of a specialized public speaking competency scale: test of reliability. Communication Research Reports, 19(1), 18-28.

Tucker, M., \& McCarthy, A. (2001). Presentation self-efficacy: increasing communication skills through service-learning, Journal of Managerial Issues, 13(2), 227-244.

Zimmerman, B. (2000). Attaining self-regulation: A social cognitive perspective. In M.

Boekaerts, P. Pintrich, \& M. Zeidner (Eds.). Handbook of self-regulation (pp.13-39). San Diego, CA: Academic press.

Zimmerman, B., \& Kitsantas, A. (2002). Acquiring writing revision and self-regulatory skill through observation and emulation. Journal of Educational Psychology, 94 (4), 660-668. 
